University of Nebraska - Lincoln

DigitalCommons@University of Nebraska - Lincoln

To Improve the Academy

Professional and Organizational Development Network in Higher Education

1995

The Case for Instructional Mentoring

Richard J. Nichols

Beverley T. Amick

Follow this and additional works at: https://digitalcommons.unl.edu/podimproveacad

Part of the Higher Education Administration Commons

Nichols, Richard J. and Amick, Beverley T., "The Case for Instructional Mentoring" (1995). To Improve the Academy. 339.

https://digitalcommons.unl.edu/podimproveacad/339

This Article is brought to you for free and open access by the Professional and Organizational Development Network in Higher Education at DigitalCommons@University of Nebraska - Lincoln. It has been accepted for inclusion in To Improve the Academy by an authorized administrator of DigitalCommons@University of Nebraska - Lincoln. 


\section{The Case for Instructional Mentoring}

\section{Richard J. Nichols}

Kean College of New Jersey

\section{Beverley T. Amick}

Kean College of New Jersey

Mentoring to enhance instructor performance in the classroom is the focus of this article. It is directed toward faculty developers conducting or developing a mentoring program, and toward individuals about to enter a mentor-mentee relationship. The article provides a look at mentoring in general, concentrates on what is required of the mentor and the mentee in order to develop teaching talent, and makes a case for the importance of mentor training. A suggested mentor training seminar concludes the article.

Mentoring is an idea that can be traced back to the ancient Greeks where Homer reports in the Odyssey that Odysseus left his son Telemechus in Mentor's care (Siegmann, 1987). Howey (1988) comments that historically the term mentor implied someone who was responsible for educating a young charge while acting as counselor and confidant much like Mentor did. Informal and formal mentoring takes place in the professions, in business, and in educational settings. Recently, institutions of higher education have begun to institute formal mentoring programs for new and returning faculty.

Over the years, the view of mentoring has broadened considerably. This is particularly true of the range of responsibilities assumed when mentoring. For example, Shea (1992) has developed a check list of twenty things that mentors may be called upon to do; while others 
have written about the varied functions and roles mentors may perform. Challenging, coaching, and dialoging are seen as mentor functions by Blackwell (1989). Luna and Cullen (1992) see it as sponsorship, networking, and role modeling as well as the development of the individual. Similarly, mentoring is viewed as being a comprehensive endeavor by Freudenthal and DiGiogio (1989) who include teaching, research, and service components in a mentoring program. Other functions are likely to include serving as a trusted colleague, developer, symbolizer of experience, coach/supervisor, and anthropologist (Head, Reiman, and Thies-Sprinthall, 1992). The way mentors perform these functions and the emphasis given to each will vary according to an organization's purposes and needs. Educational institutions concerned with providing high quality instruction, which translates into assuring that the novice instructor is pedagogically knowledgeable and practiced, will want to give emphasis to each of these functions as crucial to the process; but particular emphasis should be given to the functions of developer, symbolizer of experience, and coach/supervisor; for it is in the performance of these functions that the traditional primary mentor may have the most impact on the enhancement of the novice's instructional knowledge and skill $\longrightarrow$ the focus of this article.

Further, this article will argue that the training of mentors is vital to the success of a mentoring program, and that such training must include a focus on teaching. Teaching is a major concern for new and non-tenured faculty. Boice (1990) found that both mentors and mentees were uncomfortable discussing teaching; yet it was one of the major topics discussed by mentors and mentees. A similar finding is reported by Holmes (1988) who found that teaching was the topic most frequently discussed by mentors and mentees.

The majority of faculty in higher education have received training in their disciplines, but not in instructional strategies. Therefore, those faculty selected as mentors need training in instructional strategies to prepare them to be successful mentors of instruction. This need is supported by Boice and Turner (1989) who found at the end of the first year of their mentoring project that more structure and encouragement were needed in order for mentors to observe mentee's teaching. In fact, Boice (1992) had to provide checklists and structure the 
observational role for the mentors so that they could discuss the act of teaching in a helpful manner with their mentees. Wunsch (1994), also, supports the idea of training mentors and mentees. Carter (1988, p.214) has written that "Learning to teach should be thought of as an intellectual activity" and when mentors perform the functions of developers, symbolizers of experience, and coach/supervisors of novice instructors they encourage such intellectual activity. As developers, mentors encourage their novices to engage in self-analysis of technical, affective, and critical dimensions of teaching; as symbolizers of experience, mentors assist their novices in building a language of teaching and in interpreting experience; as coach/supervisors mentors can provide cycles of assistance for the novice within a clinical supervision model of teaching (Head, et al. 1992).

Giving emphasis to the functions of developer, symbolizer of experience, and coach/supervisor, each of which directly supports instructional enhancement, points up the fact that coaching in and of itself is not enough for real instructional improvement, while at the same time such emphasis supports a point made by Glickman (1990a) that mentoring is more than a budding relationship of social support. For Glickman, mentoring is a relationship between experienced and novice faculty that inquires about and strengthens instructional competence. He writes: "In its fullest sense [mentoring] is a process that says to people coming into teaching that observing, meeting, discussing, and making informed decisions about teaching and learning is a professional work." (p. viii)

Accepting Glickman's concept of mentoring as a process to inquire about and strengthen instructional competence leads to the question of what is needed to make such a process work. What are the characteristics and skills the mentor and mentee must bring to a process focusing on instruction?

\section{Desirable Mentor Characteristics and Skills}

There are many areas in which mentors must be knowledgeable, and there are a variety of mentoring skills to be mastered. Instructional mentors need a training program to prepare them for the mentoring role. They need to understand their responsibilities as well as those of 
the mentee. In addition, they need to acquire and/or develop the skills involved in mentoring. Mentors need to be knowledgeable about adult learning and development to work effectively with proteges. Mid-career individuals who are known as good teachers are those who are likely to be selected to serve as instructional mentors. These individuals are at a point in their lives where they are reappraising their professional career and accomplishments and readjusting their goals. The mentee, on the other hand, is generally a young adult, new to teaching, who is being initiated into the institution and who is trying to meet his/her professional objectives (Head et. al. 1992). Jackson and Simpson (1994) argue for mentoring junior faculty who have not had any full-time teaching experience as a way to help them reach their teaching effectiveness goals. The mentor must be aware of the differences in orientation and stages of development in order to effectively guide the mentee.

Knowledge of curriculum and the resources of the institution is another essential for the mentor. The mentor needs to understand the relationship between general education and major requirements as well as the relationship of specific courses to each of these. The mentor is responsible for helping the protege understand how the courses he/she is assigned fit into the curriculum structure. A responsibility of the mentor is to familiarize the protege with the instructional resources available. These include library, audiovisual, technological, student learning assistance programs, and faculty professional development opportunities.

The third area of expertise needed by instructional mentors is a knowledge of teaching strategies and techniques. Not only will the mentor be called upon to discuss the dynamics of teaching, but he/she will be asked to observe the mentee's class or the mentee may ask to visit the mentor's class to observe a particular strategy which the mentor will model. Frequently, new instructors come prepared to imitate the teaching behavior of their professors, and this may have been largely lecture. With the diversification of the student body in many colleges and universities, it is necessary for the instructional mentor to have knowledge of and the ability to guide the mentee in the use of a variety of strategies such as discussion, cooperative groups, small groups, and case studies. 
Student assessment is a fourth area in which mentors need to be prepared to guide the mentees. Over the years, the mentors have developed a variety of strategies for assessing student progress. Some of these are formal while others are informal. The new faculty member knows only the formal techniques that have been experienced as a student. The senior faculty member needs to be consciously aware of the techniques, both formal and informal, that are used in his/her classes and to share these with his/her protege. These can be techniques for assessing student knowledge of content, skills, attitudes, and/or values. An informal assessment approach, for example, might be something as simple as a review question based on the last class, which is placed on the board. Upon entering the room, students jot down their individual responses to the question. These responses may be collected, shared with a peer, briefly discussed in the whole class setting, or used in any combination of these three ways.

The fifth area of knowledge and skills needed by the mentor is that of modeling. Not only will the mentor model instructional strategies, but he/she will model conferencing skills with students and colleagues as well.

\section{Supporting Skills of Mentors}

In addition to the five areas of expertise discussed above, instructional mentors need skills in planning, observing, and conferencing. A training program for instructional mentors needs to focus on these three aggregates of skills.

First year faculty need guidance in planning for teaching. Boice (1990) found that new faculty spent an average of 23.5 hours a week preparing lectures and many received mediocre student ratings. Instructional mentors can help their proteges with class planning. They can discuss issues such as who are the learners and what prior knowledge do they bring to the course. New faculty can be guided in the development of a semester plan and then in the development of plans for specific class sessions. Helping the mentee understand the dynamic nature of the act of teaching and then the planning process for teaching is a key mentor function. Consideration needs to be given to helping the new instructor clarify and articulate the objectives for 
class sessions. Then helping him/her determine the content and the best instructional procedure to achieve the objectives follows naturally. At this point timing may be an issue and an instructional mentor can assist with the development of this skill. The final step is for the mentor to help the mentee with procedures for assessing student learning.

In order to help new instructors, it is necessary for the instructional mentor to observe them teaching. Due to the dynamic nature of classroom interactions, observers need a framework for viewing what is happening in the class. Instructional mentors can be prepared to observe from a variety of vantage points, to determine a focus for each observation, and to report objectively to the mentee on their observations. Hyman (1986) suggests a variety of reasons for observing. These range from observing to know what is happening in the protege's classroom, to observing to create dissonance and facilitate change. The key to successful observation is being clear about the reason for the observation, the specific aspects to be observed, and being objective in the observation.

The third set of skills mentors need are those of conferencing. After observing, the mentor will need to have a conference with the mentee about what the mentor focused on in the class. With preparation, mentors can learn conferencing skills that allow them to be objective about what they have seen and to report to the protege on the specifics of the observation. The language used should be descriptive rather than judgmental. The mentor can make statements such as, "There were 20 women and 15 men in the class." "Eight men and two women spoke during the first thirty minutes of the class discussion." These are descriptive statements. Each statement tells the instructor exactly what transpired in the class with no indication of whether this is good or bad. This type of conference allows for the focus to be placed on teaching skills, student behavior, professional knowledge and planning.

\section{Desirable Mentee Characteristics and Skills}

To this point the discussion has focused on the role of the mentor and what he/she must bring to the mentoring process. However, two 
people are involved - the mentor and the mentee - and for the process to be a success the mentee must also contribute. Cunningham (1994), writing on mentoring for professional development in general, has suggested that in successful mentoring relationships the mentee brings to the relationship a desire to learn, interest in people, orientation toward a goal, conceptual ability, initiative, ability to be introspective, and assertiveness.

In an educational setting the following, slightly more specific set of characteristics and skills is deemed desirable for the novice instructor in the mentee's role: (1) knowledge of academic discipline, (2) desire to improve pedagogical knowledge and skills, (3) interest in students, (4) conceptual ability, (5) conferencing skills, (6) ability to be introspective, (7) assertiveness.

The relationship of knowledge of academic discipline and the desire to improve pedagogical knowledge and skills and their importance to the instructional process is summed up in a quotation from Northrop Frye cited in Schoenfeld and Magnan (1994): he says, "A teacher who is not a scholar is soon going to be out of touch with his own subject, and a scholar who is not a teacher is soon going to be out of touch with the world." (p. 162)

When the mentee is lacking in knowledge of his/her academic discipline and has little desire to improve his/her pedagogical knowledge and skills, whatever mentoring takes place is almost certainly doomed to fail. If, however, these two characteristics are present and are accompanied by an interest in students - who they are and how their learning can be facilitated - foundations for mentee contributions help form a successful mentoring experience.

For the mentoring experience to be truly successful, however, the remaining desirable mentee characteristics and skills of conceptual ability, conferencing skills, ability to be introspective, and assertiveness must also be present. The first of these, conceptual ability, has been discussed by Glickman (1990b). He categorizes how a mentee in each of three levels of abstract thinking is likely to respond to a given situation. Glickman notes, for example, that the mentee with a low level of abstract thinking will demonstrate confusion about a situation, will not know what can be done, will ask to be shown, and will use habitual responses to varying situations. The individual with 
a high level of abstract thinking, on the other hand, will define the situation by drawing relationships between several sources of information, can relate the information to a change in instructional practice, may generate many alternative responses, and can evaluate the consequences of each response and choose the most likely to succeed. Obviously the individual who comes to the mentoring process with a high level of abstract thinking will make the mentor's work easier.

Conferencing skills are also crucial to a successful experience, and this is a set of skills that can be developed during the process if the mentor and the mentee will devote some time to such skill development. To help the mentee get the most from a conference following an observed teaching performance, Hyman (1986) has developed a list of things a mentor should review with a mentee. They are guidelines for receiving feedback in a helpful, meaningful way and include such things as: focusing on what is being said rather than how it is said; focusing on feedback as a learning tool rather than as criticism; focusing on accepting the information and suggestions offered rather than defending what you did; focusing on seeking specific, concrete suggestions regarding your performance rather than abstractions about your approach or attitude; focusing on clarifying what's been said to you rather than passively absorbing a lecture from someone; checking the feedback you received from a person by summarizing the main points for both of you.

The items on the Hyman list are particularly pertinent for instructional improvement, and in dealing with them, the two final items on the desirable mentee characteristics and skills list, introspection and assertiveness, come into play. The ability to be introspective and to reflect on the information provided on one's teaching during a conference is particularly useful in the mentee's determining what's working, what's not working as well as it might, and what might be done about it; while assertiveness is a characteristic that can be very useful in the conference itself, especially when seeking specific concrete suggestions and clarifications from the mentor. If the mentor and the mentee are working in a supportive environment and enter the relationship with all the characteristics and skills previously listed, a successful experience is assured. 


\section{Matching Mentor and Mentee}

A review of the literature on mentoring shows a concern about matching mentors and mentees. Luna and Cullen (1992) argue that new female faculty should be mentored by other females. Luna and Cullen feel this is critical because of the issue of balancing family and work. These authors also argue for same-race mentoring relationships. In a program where senior tenured women faculty were matched with junior women faculty, Wunsch and Johnsrud (1992) found the pairings were most successful in related disciplines or where there were common personal interests. Matches in the same department or in completely unrelated disciplines were not as successful. In an extensive study, Boice (1990) found that mentoring was effective in an institution of higher education. Contrary to the position of Luna and Cullen (1992), Boice (1990), in his research on mentoring, found that sex and ethnicity were not critical factors in the success of the mentoring relationship. In addition, in the same study, Boice (1990) found that mentors and mentees from different departments were as successful as the pairs from the same department. While the results of Wunsch and Johnsrud's (1992) work and Boice's (1990) work show some contradictions, they do agree on the need for providing training for the mentors. A key factor in a successful mentoring relationship seems to be the process used in mentoring rather than who the mentor and mentee are. This is why training is an important component of mentoring programs (DeJong, Hartman, and Fisher-Hoult, 1990).

\section{Summary and Conclusion}

Three major points have been the focus of this article: (1) a mentoring process focusing on instructional competence offers an effective means for developing teaching talent; (2) a mentor concerned with enhancing instructional performance may be called upon to perform a variety of functions, particularly the functions of developer, symbolizer of experience, and coach/supervisor; (3) faculty who become mentors often have had little experience in performing the functions of developer, symbolizer of experience, and coach/supervisor, and a training program for mentors which focuses upon the 
knowledge and skills needed to successfully perform each of these functions may be of considerable value.

Belief in the value of such training has lead to the development and presentation of a mentoring seminar which addresses the mentor's role, adult and professional development, planning, observation techniques, and conferencing techniques. The objectives of the seminar are as follows:

Participants will:

A. understand the mentor's and the mentee's role within the context of a professional development program;

B. know and understand current theories of adult and professional development and their relationship to the mentoring process;

C. know and understand the types and functions of planning and ways to assist mentees in the development of plans;

D. demonstrate knowledge of observational techniques and skills in observing mentees;

E. demonstrate knowledge of conferencing strategies and skills in employing these strategies, particularly in providing descriptive feedback.

For each objective a module has been developed which may be delivered in $1 \frac{1}{2}$ to $2 \frac{1}{2}$ hours. Active learning strategies such as group discussion, role playing, simulations, group problem solving, and case studies are used as the dominant forms of instruction in presenting these modules which deal with the following topics:

\section{A. The Mentor's Role}

1. Overview of mentoring within a professional development program

2. The mentor's functions

3. Skills and characteristics needed for effective mentoring
a. Mentor
b. Mentee

4. Support vs. evaluation

B. Adult and Professional Development 
1. Beliefs/behavior continuum for mentors

2. Prior learning of mentees

3. Learning stages

4. Developmental complexity

a. Mentee

b. Mentor

5. From coach to consultant to colleague

C. Planning

1. Mentee's developmental stage and planning

2. The functions of planning

3. Types of plans

4. Planning models

5. Pre-planning decisions

6. Plans and subsequent teaching actions

D. Observations

1. Planning models and observations

2. Indicators of effective teaching

a. Direct

b. Indirect

3. Observation of the mentee

a. Why one looks

b. What one looks for

c. How to look

4. Five types of mentoring statement processes

E. Conferencing

1. Mentoring statement processes and conferencing

2. Three types of conferences

3. Developmental conferencing strategies

4. Communication skills: listening, using descriptive language

5. Soliciting and offering alternative instructional techniques and strategies

6. Helping the mentee to develop conferencing skills

This seminar has served to enhance mentors' knowledge and skills, which in turn enhances their work with their mentees, which then enhances the mentees' instructional performances. From this it is concluded that when two adults - a trained and experienced faculty 
member and a novice instructor-understand themselves and each other and work in a supportive environment which emphasizes quality instruction, positive results will show in the classroom.

\section{References}

Blackwell, J.E. (1989). Mentoring: An action strategy for increasing minority faculty. Academe, 75 (5), 8-14.

Boice, R. (1992). Lessons learned about mentoring. In M.D. Sorcinelli \& A.E. Austin (Eds.), New Directions for Teaching and Learning: Developing New and Junior Faculty, No. 50, (pp. 51-61). San Francisco: Jossey-Bass.

Boice, R. (1990). Mentoring new faculty: A program for implementation. The Journal of Staff, Program and Organizational Development, 8 (3), 143-163.

Boice, R. and Turner, J.L. (1989). The fipse-csuld mentoring project for new faculty. To Improve the Academy, 8 117-139.

Carter, K. (1988). Using cases to frame mentor-novice conversations about teaching. Theory Into Practice, 27, 214-222.

Cunningham, J.B. (1994). Using mentoring for professional development. In J.W. Pfeiffer (Ed.), The 1994 annual: Developing human resources, (pp. 227-241). San Diego: Pfeiffer \& Co.

DeJong, C., Hartman, M. and Fisher-Hoult, J. (1994). Mentoring new faculty. The Journal of Staff, Program and Organization Development, 12 (1), 41-49.

Freudenthal, N.R. and DiGiogio, J. (1989). New faculty mentoring: the institution as mentor. The Journal of Staff, Program and Organization Development, 7 (2), 67-72.

Glickman, C. (1990a). In T. Bey and C.T. Holmes (Eds.), Mentoring: Developing successful new teachers, (pp. VII-VIII). Reston, VA.: Association of Teacher Educators.

Glickman, C. (1990b). Supervision of instruction: A developmental approach (2nd ed.). Boston: Allyn and Bacon.

Head, F., Reiman, A., and Thies-Sprinthall, L. (1992). The reality of mentoring: Complexity in its process and function. In T. Bey and C.T. Holmes (Eds.), Mentoring: Contemporary Principles and Issues, (pp. 5-24). Reston, VA: Association of Teacher Educators.

Holmes, S. (1988). New faculty mentoring: Benefits to the mentor. The Journal of Staff, Program and Organization Development, 6 (1), 17-20.

Howey, K. (1988) Mentor-teachers as inquiring professionals. Theory Into Practice, 27, 209-213.

Hyman, R. (1986). School administrator's faculty supervision handbook. Englewood Cliffs, N.J.: Prentice-Hall, Inc.

Jackson, W.K. and Simpson, R.D. (1994). Mentoring new faculty for teaching and research. In M.A. Wunsch (Ed.), New directions in teaching and learning: Mentoring revisited: Making an impact on individuals and institutions, No. 57, (pp. 65-72). San Francisco: Jossey-Bass. 
Luna, G. and Cullen, D.L. (1992). Mentoring women and minorities: Application to higher education. The Journal of Staff, Program and Organization Development, 10 (3), 133-139.

Schoenfeld, A.C. and Magnan, R. (1994). Mentor in a manual: Climbing the academic ladder to tenure. (2nd ed.) Madison, WI: Magna Publications, Inc.

Shea, G. (1992). Mentoring: A practical guide. Menlo Park, CA: Crisp Publications, Inc.

Seigmann, K.B. (Ed.) (1987). Benet's readers encyclopedia. (3rd ed.) New York: Harper Collins Publishers, Inc.

Wunsch, M.A. (1994). Developing mentoring programs: Major themes and issues. In M.A. Wunsch (Ed.) New directions in teaching and learning: Mentoring revisited: Making an impact on individuals and institutions, No. 57 (pp. 27-34). San Francisco: JosseyBass.

Wunsch, M.A. and Johnsrud, L.K. (1992). Breaking barriers: Mentoring junior faculty women for professional development and retention. To Improve and Academy, 11, 175-188. 